\title{
Mobility of Organotin Pesticides: Azocyclotin And Cyhexatin In Clayey And Sandy Soils From The Northern Paraná State - Brazil
}

\section{Andre A.A Lima}

State University of Londrina

Bruno S.D Onishi

State University of Londrina

Lycio S. Watanabe

State University of Londrina

Maria J.Santos ( $\nabla$ mjyabe@uel.br)

State University of Londrina https://orcid.org/0000-0003-3485-5413

\section{Research Article}

Keywords: organometallic compounds, soils, sorption, HPLC-PDA, hysteresis, mobilization

Posted Date: December 1st, 2021

DOI: https://doi.org/10.21203/rs.3.rs-882078/v1

License: (9) This work is licensed under a Creative Commons Attribution 4.0 International License.

Read Full License

Version of Record: A version of this preprint was published at Environmental Earth Sciences on April 1st, 2022. See the published version at https://doi.org/10.1007/s12665-022-10351-7. 
Mobility of organotin pesticides: azocyclotin and cyhexatin in clayey and sandy soils from the Northern Paraná state - Brazil

\author{
Andre A.A Lima ${ }^{1}$, Bruno S.D Onishi ${ }^{1 \dagger}$, Lycio S. Watanabe ${ }^{1 \dagger}$ \\ and Maria J. Santos ${ }^{1{ }^{*} \dagger}$ \\ ${ }^{1}$ Chemistry Department, State University of Londrina, Rod. \\ Celso Garcia Cid -PR445, Londrina, 86051-990, Paraná, Brazil.
}

*Corresponding author(s). E-mail(s): mjyabe@uel.br; Contributing authors: andre.andrade.aires@uel.br; bruno.onishi14@gmail.com; shinjiwatanabe2003@hotmail.com; $\dagger$ These authors contributed equally to this work.

\begin{abstract}
Azocyclotin and cyhexatin are pesticides commonly used in mite control. However, these organotin compounds are highly harmful to the aquatic ecosystem and supposedly mobile in the soil. In addition to not existing defined rules of use, few studies have been carried out on organotins' behavior and environmental control. Liquid chromatography has been pointed out for the OTC quantitation because of gas chromatography's thermal stability and derivatization limitations. Hence, a new high-performance liquid chromatography method with photodiode array detection (HPLC-PDA) was developed for quality assurance and quality control (QA/QC) and environmental performance assessment purposes. Hysteresis index $(H I)$ and mobilization factor were determined from sorption/desorption in sandy and clayey soils to assess mobility and environmental risk. Mobilization was observed for the two compounds by applying the dual-mode Freundlich-Langmuir model to the isotherms. Azocyclotin showed greater mobility, 23\% and $19 \%$, and $H I$ of -0.15 and $7.8 \times 10^{-4}$ for clayey and sandy soil samples, respectively. Although cyhexatin was practically immobile for both soil samples, it can be mobilized as an azocyclotin metabolite, increasing the environmental impact and risk for agricultural uses.
\end{abstract}


Keywords: organometallic compounds, soils, sorption, HPLC-PDA,

\section{Introduction}

World population growth requires a high demand for food and agricultural productivity, fueled by new technologies and increased use of pesticides. Although pesticides are an essential tool to control undesired living species, their toxicity may risk human beings and other non-target species (Fent and Mueller, 1991). Pests such as pathogenic fungi and mites in apple, citrus, eggplant, soybean, coffee, and cocoa have been efficiently controlled by organotin compounds (OTC) such as azocyclotin and cyhexatin (Godoi et al, 2003; Blunden and Evans, 1990). However, environmental risk is associated with its toxicity to the aquatic ecosystem and human health (Fent and Mueller, 1991; Kanimozhi et al, 2016). Adverse effects can be observed when the maximum residue limit for the total of azocyclotin and cyhexatin (expressed as cyhexatin) exceeds $2.0 \mathrm{mg} \mathrm{kg}^{-1}$ for human consumption (Ning et al, 2015; EU, 2012). Cyhexatin, a metabolite of azocyclotin, is one the most toxic among triorganotin compounds. Health problems such as irreversible corneal opacity, high reproductive toxicity even at low concentrations, and animal teratogenicity make OTC a target for environmental behavior studies (Fent, 1996; PubChem, 2017a,b). OTC constitute Stockholm's persistent organic pollutants and share the same characteristics of being persistent, toxic, bioaccumulative, and capable of traveling long distances through different means (Ming et al, 2012). Concerning the matrix, OTC degradation in soils is considered to be longer, with a halflife of about several years to decades in soil compared to the water column (Furdek et al, 2016). Consequently, soils and sediments emerge as secondary and persistent OTC sources, becoming a potential threat in affected environments. Organotin compounds affect the ecosystem, and according to Ebdon et al (2001) should be listed as global pollutants.

The 1,2,4-triazole group characterizes the azocyclotin and the hydroxyl group the cyhexatin (Fig 1). These groups have different affinities for soil components, following mechanisms of sorption, complexation, dissolution, and diffusion, which can occur concurrently, and are highly dependent on factors such as organic matter, pH, and ionic strength (Godoi et al, 2003; Blunden and Evans, 1990). Cyhexatin is an azocyclotin metabolite obtained by simple hydrolysis. In soils, cyhexatin takes about 50 days to degrade to dicyclohexyltin oxide $\left(\mathrm{C}_{12} \mathrm{H}_{22} \mathrm{SnO}\right)$, cyclohexylstannoic acid $\left(\mathrm{C}_{6} \mathrm{H}_{11} \mathrm{SnO}_{2} \mathrm{H}\right)$ and tin dioxide $\left(\mathrm{SnO}_{2}\right)$ (Muller and Markus, 1987), which also are important compounds on environmental risk assessment (Oliveira and Santelli, 2010).

Currently, the primary technique used to quantify OTC is chromatography. Several methods have been developed annually to separate and quantify 

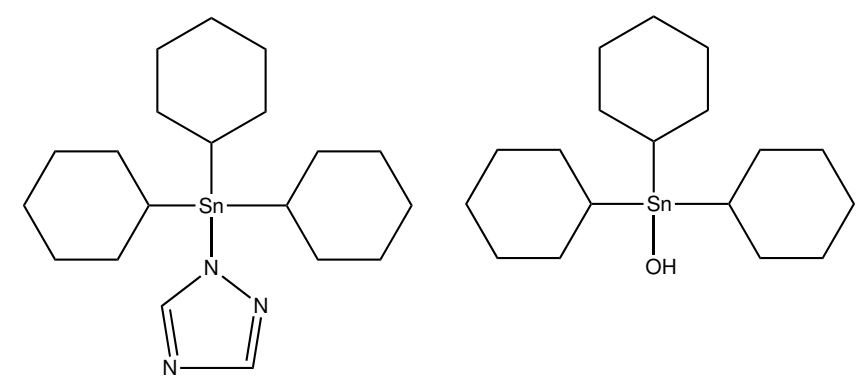

Fig. 1 Azocyclotin and cyhexatin structures

pesticides by gas chromatography (GC) and high-performance liquid chromatography (HPLC). High-performance liquid chromatography (HPLC) has been the most applied technique. Due to some limitations on thermal stability and derivatization requirements in gas chromatography (Perez and Barasoain, 1983), studies have pointed to the use of photodiode array (PDA) and fluorescence detectors to quantify azocyclotin and cyhexatin pesticides (Joan et al, 1992). The main advantages of liquid chromatography for OTC analysis are broad applicability, high resolution, fast analysis, high sensitivity, high reproducibility, and separation of compounds, in addition to being a quantitative and easily automated technique. In this sense, HPLC-PDA proves to be a more straightforward technique for the analysis of organotin compounds.

Studies on environmental mobility for azocyclotin and cyhexatin have not been reported in the literature. Hence, the hypothesis that these pesticides mobilize in the environment, increasing the risk of biota contamination, motivated us to study the sorption and desorption processes and their mobility in two types of soil from Southern Brazil. Additionally, an HPLC-PDA method is herein developed and validated to quantify the target compounds in soil.

\section{Material and Methods}

\subsection{Material}

Clayey and sandy soil samples were collected in North Parana State, Southern Brazil $\left(24^{\circ} 24^{\prime} 57.5^{\prime} \mathrm{S} 51^{\circ} 00^{\prime} 0.6^{\prime \prime} \mathrm{W}\right.$ and $\left.23^{\circ} 00^{\prime} 57.4^{\prime \prime} \mathrm{S} 51^{\circ} 11^{\prime} 28.3^{\prime \prime} \mathrm{W}\right)$, at $20 \mathrm{~cm}$ depth. The samples were dried, sieved in a $2 \mathrm{~mm}$ stainless steel sieve, and preserved in properly decontaminated polyethylene flasks.

Solutions were prepared from $\mathrm{CaCl}_{2} \cdot 2 \mathrm{H}_{2} \mathrm{O}$ (Synth, analytical grade), azocyclotin reference material (ACT, Sigma-Aldrich, 99,9\%, CAS-No.[410831108]), cyhexatin reference material (CHT, Dr. Ehrenstorfer GmbH, 97,4\%, CAS-No.[13121-70-5]), acetonitrile (ACN, PANREAC, HPLC grade), and dichloromethane (DM, Biotec, HPLC grade). Ultrapure water was obtained from Milli-Q ${ }^{\circledR}$ Simplicity 185 water purification system. 


\subsection{Characterization of the soil samples}

The $\mathrm{pH}$ of the soil samples was measured in water and $\mathrm{KCl}$ at 1:2.5 soil:solution ratio to calculate $\Delta \mathrm{pH}$ and determine the surface charge. The organic matter (OM) was quantified by oxidizing the samples with potassium dichromate in a sulphuric medium (Embrapa, 2011; Walkley and Black, 1934). The cation exchange capacity (CEC) was determined by the sum of bases $\left(\mathrm{K}^{+}, \mathrm{Ca}^{2+}\right.$, $\left.\mathrm{Mg}^{2+}\right)$, and exchangeable aluminum $\left(\mathrm{H}^{+}+\mathrm{Al}^{3+}\right)$. The granulometry was determined by the hydrometer method based on the sample density change in water suspensions upon the particle settling (Cheng and Schachman, 1955; Embrapa, 2011). Infrared spectra were recorded on a Prestige-21 spectrometer (Shimadzu, Kyoto, Japan), with a resolution of $2 \mathrm{~cm}^{-1}$ and 20 accumulation scans ranging from 4000 to $400 \mathrm{~cm}^{-1}$. The samples were analyzed in $\mathrm{KBr}$ discs with $1 \%$ mass loading.

X-ray powder diffraction (XRD) patterns were obtained in a Panalytical X'Pert Pro MPD diffractometer (Almelo, The Netherlands) with CuK $\alpha$ radiation $(\lambda=1.5418 \stackrel{\circ}{A}), 40 \mathrm{kV}$ and $30 \mathrm{~mA}$, in $2 \theta$ scanning from $5^{\circ}$ to $80^{\circ}$ each $0.03^{\circ}$ $\min ^{-1}$. The diffraction patterns were acquired by the XPert HighScore software. A Ray-Ny EDX 720 Shimadzu equipment was used for EDXRF analysis in quantitative mode with a $3 \mathrm{~mm}$ collimator, air atmosphere, $50 \mathrm{~s}$ analysis time, $50 \mathrm{kV}$ X-ray and $30 \mathrm{~mA}$ current.

\subsection{Sorption and desorption experiments}

Standard stock solutions of ACT in ACN and CHT in 1.0\% (v/v) DM in ACN (eluent) $110.0 \mathrm{mg} \mathrm{L}^{-1}$ were prepared for the sorption experiments. Blanks were prepared by adding $10.0 \mathrm{~mL}$ of $0.010 \mathrm{~mol} \mathrm{~L}^{-1} \mathrm{CaCl}_{2} \cdot 2 \mathrm{H}_{2} \mathrm{O}$ to $2.0 \mathrm{~g}$ of soil sample. Isotherms were built ranging $\mathrm{ACT}$ or $\mathrm{CHT}$ initial concentration from 2.0 to $50.0 \mathrm{mg} \mathrm{L}^{-1}$. The OTC solutions were added to $0.010 \mathrm{~mol} \mathrm{~L}-1 \mathrm{CaCl}_{2} \cdot 2 \mathrm{H}_{2} \mathrm{O}$ and $2.0 \mathrm{~g}$ of soil sample up to $10 \mathrm{~mL}$ to keep ionic strength and achieve adequate peak resolution (Gui et al, 2016). The suspensions were equilibrated at $30 \mathrm{rpm}$ for $24 \mathrm{~h}$ at $22 \pm 2^{\circ} \mathrm{C}$ and centrifuged at $3048 \mathrm{rpm}(1350 \times g)$ for $5 \mathrm{~min}$ (EV025 Evilab). A $5.0 \mathrm{~mL}$ aliquot of the supernatant was then liquid-liquid extracted with ACN in an ultrasonic bath. The sample was filtered (Filtril 0.22 $\mu \mathrm{m}$ nylon) and analyzed by HPLC-PDA, described in Section 2.4. The assays were carried out in triplicate and the pre- and post-sorption $\mathrm{pH}$ was measured.

Desorption experiments started from the higher sorption concentration $\left(50.0 \mathrm{mg} \mathrm{\textrm {L } ^ { - 1 }}\right.$ ) in a fractional way by exchanging $5.0 \mathrm{~mL}$ of the supernatant per $5.0 \mathrm{~mL}$ of $0.010 \mathrm{~mol} \mathrm{~L}^{-1} \mathrm{CaCl}_{2} \cdot 2 \mathrm{H}_{2} \mathrm{O}$ to increase ionic strength gradually. The suspension was equilibrated at $30 \mathrm{rpm}$ for $24 \mathrm{~h}$. Desorption procedure was repeated sequentially until the OTC were no longer detected. The $\mathrm{pH}$ was determined at the start and end of each fraction. Samples were taken at each step, ACN extracted and analyzed by HPLC-PDA using the same procedure as the sorption samples.

ANOVA, Student's t, and F statistical tests were applied at 95\% confidence interval and $5 \%$ significance level for testing two hypotheses on the sorbed 

no significant difference between the two soil samples in the sorption process, and $\mathrm{H}_{1 a}$ - a significant difference between the soil samples in the sorption process. Hypotheses on the sorption and desorption $\Delta \mathrm{pH}$, called $\mathrm{H}_{0 b}$ and $\mathrm{H}_{1 b}$, were also statistically evaluated (see results in SI, Statistical tests).

\subsection{Chromatographic method for quantitation of azocyclotin and cyhexatin}

A chromatographic method was developed for azocyclotin and cyhexatin quantitation from sorption and desorption procedures. Analysis of ACT and CHT was carried out on a Shimadzu Prominence ${ }^{\circledR}$ HPLC using a Hypersil GOLD PFP column $(150 \times 4.6 \mathrm{~mm}$ i.d.; $3 \mu \mathrm{m}$ particle size, Thermo Scientific, USA) and PDA detector (SPD-20A) at $205 \mathrm{~nm}$. The mobile phase was ACN and ultrapure water acidified with $\mathrm{H}_{3} \mathrm{PO}_{4}, \mathrm{pH}=2.5$ (Synth, analytical grade) in the 70:30 ratio. The injection volume was adjusted to $20 \mu \mathrm{L}$ and the temperature to $40^{\circ} \mathrm{C}$. Chromatograms were obtained from sorption and desorption extracts at $205 \mathrm{~nm}$ (Ning et al, 2015; Gui et al, 2016). Data acquisition and integration of chromatographic peaks were carried out with LC Solutions software (Shimadzu corp., Japan).

\subsection{Chromatographic method validation}

The chromatographic method developed for azocyclotin and cyhexatin quantitation from sorption and desorption procedures was validated. Stock solutions of $110.0 \mathrm{mg} \mathrm{L}^{-1} \mathrm{ACT}$ in ACN and $110.0 \mathrm{mg} \mathrm{L}{ }^{-1} \mathrm{CHT}$ in ACN and 1.0\% DM were prepared, and the analytical curve constructed $\left(1.0\right.$ to $\left.110.0 \mathrm{mg} \mathrm{L}^{-1}\right)$ from the external standard method for QC/QA purposes. It is worth noting the use of DM with ACN for better solubilization of cyhexatin. The method was validated in terms of linearity, precision, repeatability, detection limit, quantitation limit, and accuracy, as described in ICH Guidelines (2005).

Linearity was assessed by standard seven-point calibration curves constructed over a range of 1.0 to $110.0 \mathrm{mg} \mathrm{L}^{-1}$. All standards and samples were injected in triplicate. The mean peak area of azocyclotin and cyhexatin was plotted versus concentration, and a linear least square regression analysis was carried out.

The intraday and interday precision was determined by analyzing three blank samples spiked with OT standard solutions at 2.0, 25.0, and $50.0 \mathrm{mg} \mathrm{L}^{-1}$, with three replicates each. Accuracy was evaluated by analyzing three replicates of three independently prepared samples at $2.0,25.0$, and $50.0 \mathrm{mg} \mathrm{L}^{-1}$ of OT standard solutions. The sensibility of the HPLC-PDA method was characterized by the limit of detection (LOD) and limit of quantification (LOQ), defined as the lowest concentration that could be detected or quantified for the signal-to-noise ratio of 3.3 and 10 , respectively. 


\subsection{Modeling the sorption-desorption isotherms}

Dual-mode Freundlich-Langmuir model and Langmuir model were fitted to the sorption and desorption isotherms using MatLab ${ }^{\circledR}$ R2010. The sorbed concentration $\left(C_{\text {sorb }}, \mathrm{mg} \mathrm{kg}^{-1}\right)$ was calculated by the difference between the initial concentration $\left(C_{i n}, \mathrm{mg} \mathrm{L}^{-1}\right)$ and the equilibrium concentration $\left(C_{e q}\right.$,

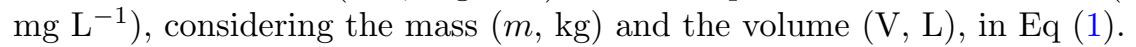

$$
C_{s o r b}=\frac{\left(C_{i n}-C_{e q}\right) V}{m}
$$

In the fractional desorption experiment, serial dilutions were prepared from the maximum sorption concentration after equilibrium. From the first dilution, step by step, $C_{i n}$ becomes half of the $C_{i n}$ from the previous step. Thereby, $C_{e q(s)}$ was obtained after each desorption step from the mass balance in Eq (2), with step $s$ varying from 0 to 7 (Constantino et al, 2018; Galunin et al, 2014). The 0 (zero) step is the maximum concentration from the sorption isotherm.

$$
C_{s o r b(s)}=\frac{\left(C_{i n(s-1)}-\frac{C_{e q(s-1)}}{2}-C_{e q(s)}\right) V}{m}
$$

Isotherms were obtained from the sorbed concentration and the concentration in solution after equilibrium. The experiments were carried out in triplicate. Langmuir model and Langmuir-Freundlich dual-mode model were applied to the isotherms. The Langmuir model is described by the Eq (3) (Langmuir, 1916; Blahovec and Yanniotis, 2009).

$$
C_{\text {sorb }}=\frac{b K C_{e q}}{1+b C_{e q}}
$$

where $C_{\text {sorb }}\left(\mathrm{mg} \mathrm{kg}^{-1}\right)$ is the sorbed concentration at equilibrium, $b$ the maximum sorption amount for the formation of a complete monolayer, $K\left(\mathrm{~L} \mathrm{~kg}^{-1}\right)$ the Langmuir constant related to sorbate-sorbent affinity, and $C_{e q}\left(\mathrm{mg} \mathrm{L}^{-1}\right)$ the concentration of the sorbate in solution at equilibrium.

In some cases, the best fit is from the dual-mode Langmuir-Freundlich model, which extrapolates the Langmuir model limitations to more than one type of interaction site, in Eq (4) (Galunin et al, 2010; Constantino et al, 2018).

$$
C_{\text {sorb }}=\sum_{j=1}^{J} \frac{b_{j}\left(K_{j} C_{e q}\right)^{n_{j}}}{1+\left(K_{j} C_{e q}\right)^{n_{j}}}
$$

where $j$ represents different types of sorption sites, $b_{j}\left(\mathrm{mg} \mathrm{kg}^{-1}\right)$ the maximum sorption capacity or the number of available sites, $K_{j}\left(\mathrm{~L} \mathrm{~kg}^{-1}\right)$ the sorbatesorbent affinity parameter and $n_{j}$ the heterogeneity of sorption sites. The lower $n_{j}$, the more irreversible the sorption (Do, 1998). 
where $C_{\text {sorb }_{i}}$ and $\widehat{C}_{\text {sorb }_{i}}$ are the $i$ th experimental sorbed OTC concentration and the $i$ th predicted point in the model of Eq (4), respectively, $N$ is the number of data points, and $p$ is the number of the fitted coefficients estimated from the model, i.e., $p=S=3 J$ is the cardinality of

$$
\mathcal{S}=\left\{b_{1}, b_{2}, \cdots, b_{J}, K_{1}, K_{2}, \cdots, K_{J}, n_{1}, n_{2}, \cdots, n_{J}\right\}
$$

The hysteresis index is defined by the area of sorption and desorption ratio from isotherms (Galunin et al, 2014), according to Eq (6).

$$
H I=\frac{\left(A_{d e s}-A_{\text {sor }}\right)}{A_{\text {des }}}
$$

The mobilization factor in $\mathrm{Eq}(7)$ is normalized and $B$, absolute value in $\mathrm{Eq}$ (8), gives the difference between the area of the desorption isotherm and the ideal desorption area (Galunin et al, 2014). ${ }^{1}$

$$
\begin{gathered}
M F=(1-H I) * B \\
B=\frac{1-A_{\text {des }}}{A_{\text {des.ideal }}}
\end{gathered}
$$

\section{Results and Discussion}

\subsection{Soil sample characterization}

Azocyclotin and cyhexatin sorption and desorption phenomena can be better understood from the physical and chemical properties of the soil samples, described in Table 1.

The negative $\Delta \mathrm{pH}$, calculated by the difference between $\mathrm{pH}_{W}$ and $\mathrm{pH}_{K C l}$, is related to negative charges on the soil surface and indicates a preference for positive ion sorption. In the case of OTC, the $\mathrm{Sn}$, as a positive center in the molecules, can be involved. Besides, the clayey soil presented a higher CEC and OM amount than sandy soil, which can be related to the sorption

\footnotetext{
${ }^{1}$ The main numerical results in this section can be generated from the MatLab script available at https://https://data.mendeley.com/datasets/2xz2w7w2jd/1. Ferreira Lima, Andre; Onishi, Bruno S. D.; Watanabe, Lycio S.; Santos, Maria Josefa; Abrao, Taufik (2021), "Mobility of organotin pesticides: azocyclotin and cyhexatin in clayey and sandy soils from the Northern Parana stateBrazil", Mendeley Data, V1, doi: 10.17632/2xz2w7w2jd.1
} 
Table 1 Physical and chemical characterization of the soil samples. Average \pm standard deviation (sd). CEC- cation-exchange capacity in $\mathrm{cmol}_{c} \mathrm{dm}^{-3} ; \Delta \mathrm{pH}=\mathrm{pH}_{K C l}-\mathrm{pH}_{W}$; OM- organic matter in \%; Major elements in $\mathrm{g} \mathrm{kg}^{-1}$; Texture in \%

\begin{tabular}{|c|c|c|c|c|c|c|c|c|c|c|c|}
\hline \multirow{2}{*}{$\begin{array}{l}\text { Soil } \\
\text { sample }\end{array}$} & \multirow[t]{2}{*}{$\mathrm{pH}_{W}$} & \multirow[t]{2}{*}{$\mathrm{pH}_{K C l}$} & \multirow[t]{2}{*}{$\Delta \mathrm{pH}$} & \multirow[t]{2}{*}{$\mathrm{CEC}$} & \multirow[t]{2}{*}{$\mathrm{OM}$} & \multicolumn{3}{|c|}{ Major elements } & \multicolumn{3}{|c|}{ Texture } \\
\hline & & & & & & $\mathrm{Fe}$ & $\mathrm{Si}$ & $\mathrm{Al}$ & Clayey & Sandy & Silt \\
\hline Clayey & 6.04 & 4.77 & -1.27 & 22.5 & 2.37 & 52.2 & 22.8 & 11.3 & 37.1 & 32.7 & 30.1 \\
\hline $\pm s d$ & 0.01 & 0.01 & 0.02 & 0.10 & 0.06 & 0.61 & 0.54 & 0.30 & - & - & - \\
\hline Sandy & 6.16 & 4.63 & -1.53 & 9.65 & 0.76 & 21.7 & 51.3 & 20.8 & 25.4 & 69.6 & 5.07 \\
\hline $\pm s d$ & 0.02 & 0.01 & 0.03 & 0.08 & 0.15 & 2.06 & 0.93 & 0.78 & - & - & - \\
\hline
\end{tabular}

capacity. The higher CEC and OM, the higher sorption capacity is expected. The potential interaction of OTC with carbonyl and phenol groups in humic substances can also influence their mobility in the soil (Giacalone et al, 2006).

The mineralogical characterization by XRD (see in Supplementary Information, Fig SI1) showed the presence of hematite, quartz, and kaolinite minerals in both soils, with the predominance of hematite in the clayey soil and quartz in the sandy soil. These results agree with the EDXRF data since Fe is the major component of the clayey soil and Si of the sandy soil. In Fig SI2, the 3453,1624 , and $1000 \mathrm{~cm}^{-1}$ bands in the infrared spectrum are characterized by structural $\mathrm{OH}^{-}$stretching, $\mathrm{CO}$ stretching of carbonyl groups from humic and fulvic acids in soils, and Si-O, respectively (Silva and Guerra, 2013).

\subsection{The Chromatographic Method}

The LOD and LOQ determined for the two matrices enriched with the reference materials (standards) were: LOD for $\operatorname{ACT}(0.1)$ and $\operatorname{CHT}(0.2) \mathrm{mg} \mathrm{L}^{-1}$ and LOQ for $\operatorname{ACT}(0.3)$ and $\operatorname{CHT}(0.9) \mathrm{mg} \mathrm{L}^{-1}$ after injecting a series of dilute standard solutions with known concentrations. Calibration curves for ACT and CHT are shown in Fig SI3. Seven-point calibration curves showed linearity, with $\mathrm{R}^{2}>0.9995$ for the standards between 1.0 and $110.0 \mathrm{mg} \mathrm{L} \mathrm{L}^{-1}$. All standards and samples were injected in triplicate. The mean peak area of ACT and CHT was plotted versus concentration, and the linear least square regression analysis was carried out. Multiple injections showed results highly reproducible and low standard error.

The intraday precision RSD for the blank spiked samples $(n=3)$ ranged from 6 to $10 \%$ for ACT and CHT. The interday RSD (n=3) was 8 and $13 \%$ for ACT and CHT, respectively. Spiked samples with the standards in three concentrations showed recovery of $71 \%$ and $105 \%$ for ACT and CHT, respectively. The results indicate an accurate, reliable, and reproducible method.

Both ACT and CHT absorb in the UV region, $205 \mathrm{~nm}$ approximately. Thus, ACN was chosen as the best mobile phase by not absorbing in the same region. Studies show that the UV-vis detector here used works very well to quantify organotin compounds and other pesticides, using ACN as mobile phase and reversed-phase HPLC columns (Xiupin et al, 2006; Tomasz and Jan, 2009).

According to Figs 2 and 3, azocyclotin standard in ACN was detected at $3.6 \mathrm{~min}$ retention time, while cyhexatin standard was at $3.4 \mathrm{~min}$. The peaks for both ACT and CHT post-sorption in the two soil samples showed a good shape and complete separation from the other soil components. Furthermore, 
Fig. 2 HPLC-PDA chromatograms for azocyclotin: PFP column, $205 \mathrm{~nm}$, ACN and ultra pure water (Mili-Q ${ }^{\circledR}$ ) acidified with $\mathrm{H}_{3} \mathrm{PO}_{4}(\mathrm{pH} 2.5)$ 70:30 as mobile phase and $20.00 \mu \mathrm{L}$ injection volume.

no interfering peak from $\mathrm{CaCl}_{2}$ electrolyte was detected. A peak from the PFP selectivity column could be seen in both chromatograms, ACT-ACN standard and CHT-ACN-DM standard, due to the pentafluorophenyl stationary phase. The $\pi$ orbitals of the PFP column interact with the $\pi$ orbitals of the 1,2,4triazole ring in azocyclotin. The ring acts as an electron donor group (Lewis base) and promotes the bond between the $\mathrm{F}$ of the column and the $\mathrm{N}$ of azocyclotin. Thus, the column becomes much more selective, performing better separation of the compounds (Gobbo et al, 2015).

\subsection{Sorption and desorption}

Sorption and desorption isotherms for ACT in the clayey and sandy soil are shown in Fig 4 and for CHT in Fig 5. The adjusted parameters are in Table 2, and the confidence intervals are presented in Figs 4 and 5. The mobilization of the OTC can be observed from the desorption isotherm below the sorption isotherm, with a negative hysteresis index - hysteretic behavior (Galunin et al, 2014). A non-hysteretic behavior would show the desorption isotherm superimposed on the sorption isotherm. Although the observed hysteresis index $(H I)$, directly related to the OT mobilization factor $(M F)$ in the soil, can be considered low, mobility is observed. The dual model was applied to adjust 
Fig. 3 HPLC-PDA chromatograms for cyhexatin: PFP column, $205 \mathrm{~nm}$, ACN and ultra pure water $\left(\right.$ Mili-Q ${ }^{\circledR}$ ) acidified with $\mathrm{H}_{3} \mathrm{PO}_{4}(\mathrm{pH} 2.5)$ 70:30 as mobile phase and $20.00 \mu \mathrm{L}$ injection volume.

the sorption isotherm, while the Langmuir model adjusted the desorption isotherm. Azocyclotin presents practically non-hysteretic behavior in sandy soil, although it has a lower maximum sorption capacity than in clayey soil. This behavior can be interpreted considering the OT's interaction with soil organic matter and the composition of each type of soil (Huang and Matzner, 2004; Gui et al, 2016). The higher organic matter amount in the clayey soil is related to the stronger interaction with the metallic center and its organic moiety. These results on OT-soil interaction are described as sorption mechanisms and supported by literature (Sparks, 1995; Essington, 2015).

Cyhexatin has a hydroxyl directly attached to the Sn, different from the azocyclotin having the triazole ring. Therefore, $\mathrm{OH}$ groups-organic matter and other interactions with soil components can interfere directly with the cyhexatin sorption and desorption processes (Jones et al, 2005; Sithole and Guy, 1987). Although the triazole ring has $\mathrm{sp}^{2}$ carbon that allows $\pi-\pi$ interaction with PFP column, cyhexatin has no $\mathrm{sp}^{2}$ carbon, and the interactions are van der Waals type. The asymptote is visible in both the adjusted sorption and desorption isotherms, and the main difference is in desorption. Cyhexatin has a hysteretic desorption profile, and there is virtually no desorption after sorption. The explanation for this profile is related to $\mathrm{OT} \mathrm{OH}^{-}$groups interacting 

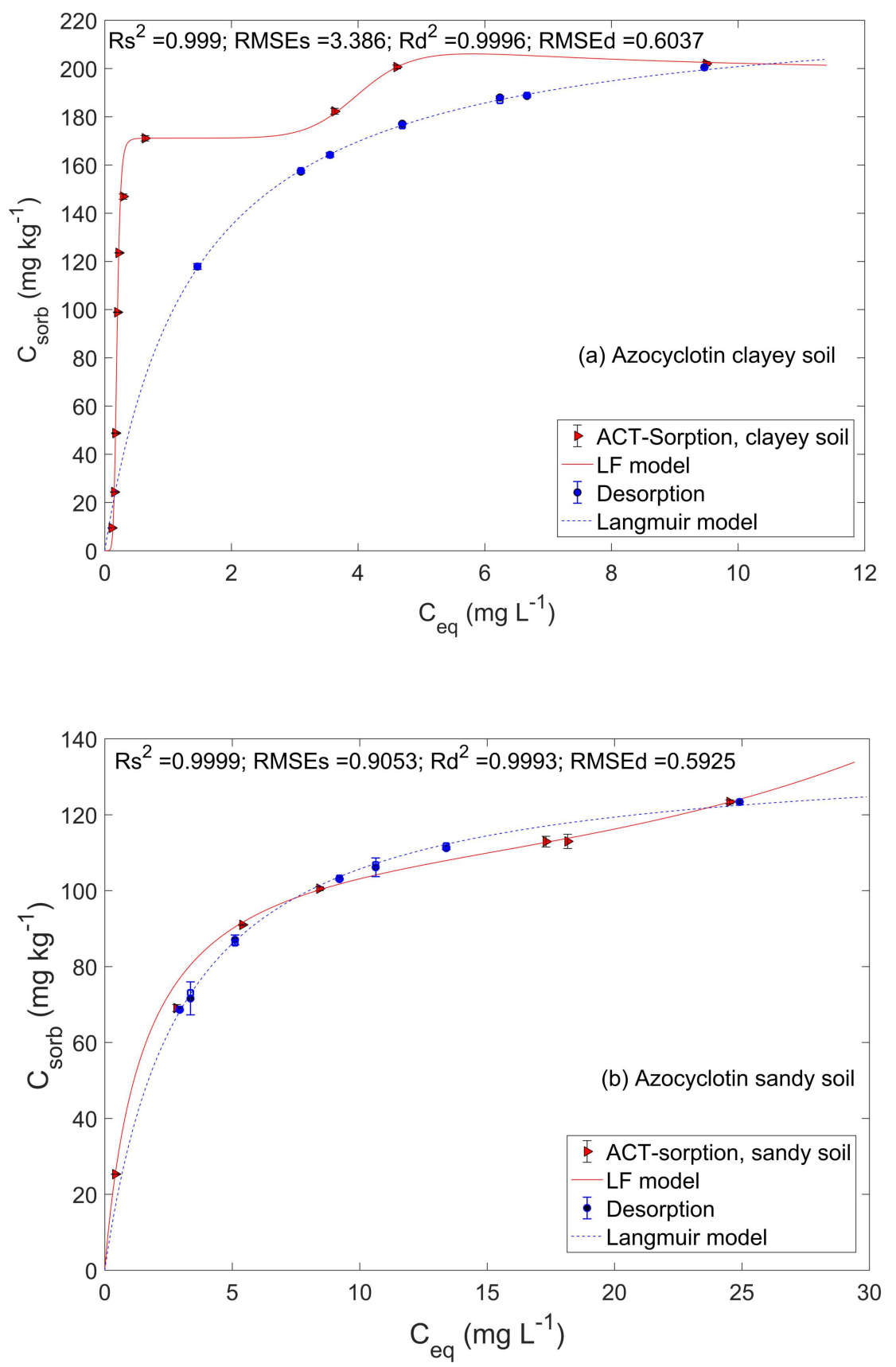

Fig. 4 Sorption and desorption isotherms for azocyclotin on (a) clayey soil and (b) sandy soil. Sorption carried out in batch, shaking $24 \mathrm{~h}$ at $22^{\circ} \mathrm{C}, \mathrm{C}_{\text {in }}$ from 2.0 to $50.0 \mathrm{mg} \mathrm{L}^{-1}$ in 2:10 solid:liquid ratio. Fractional desorption ( 7 points; each point is the mean \pm sd of three experiments) from the highest sorption initial concentration, taking aliquots of half the volume for analysis, filling with the electrolyte solution in the same volumetric ratio every $24 \mathrm{~h} . \mathrm{R}^{2}$ is determination coefficient and RMSE root mean square error, with $s$ or $d$ associated with sorption and desorption, respectively. 95\% confidence intervals are shown for seven data point triplicate 
12 Mobility of organotin pesticides: azocyclotin and cyhexatin in clayey and sandy soils
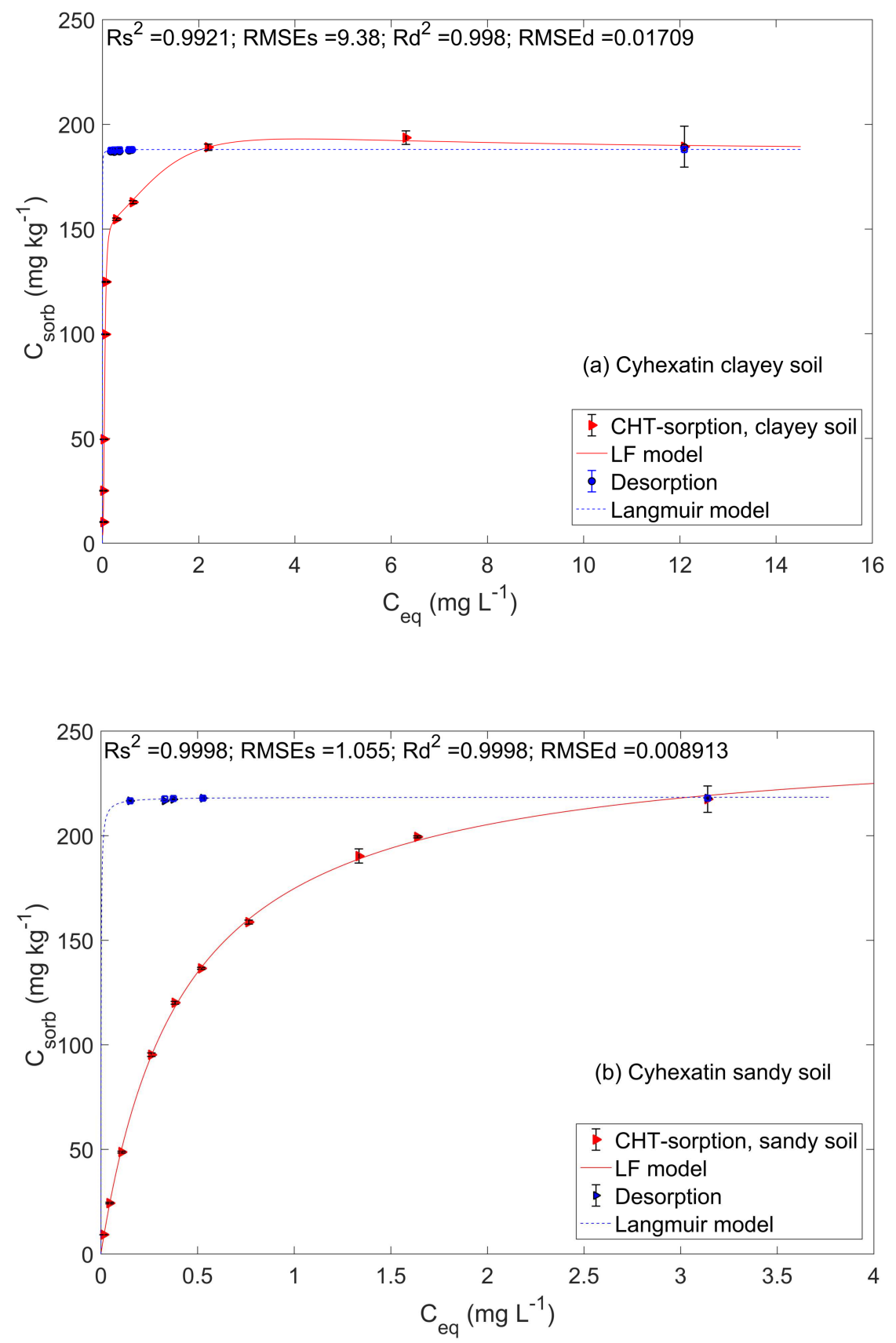

Fig. 5 Sorption and desorption isotherms for cyhexatin on (a) clayey soil and (b) sandy soil. The experimental conditions are the same as in Fig $4.95 \%$ confidence intervals are shown for ten data point; each point is the mean \pm sd of three experiments 
with the soil, in addition to the $\Delta \mathrm{pH}$ for both OT and soils (Jones et al, 2005; Sithole and Guy, 1987). The ACT $\Delta \mathrm{pH}$ was prior in the positive region of the curve considering that $\mathrm{pH}_{\text {final }}>\mathrm{pH}_{\text {initial }}$, and with the OT initial concentration increasing, the curve gone to a $\Delta \mathrm{pH}<0$ (Fig 6). The curve for CHT always shows $\Delta \mathrm{pH}<0$ and, therefore $\mathrm{pH}_{\text {final }}<\mathrm{pH}_{\text {initial }}$. When $\mathrm{OH}^{-}$ directly bound to the metal center is released, Sn becomes more electronically deficient and binds more strongly to the soil surface (Dhananjay et al, 2016).

The sorption isotherm has an H-type profile (High Affinity), which is a particular case of the Langmuir isotherm whose sorbate has a high affinity for the sorbent, considering a very pronounced increase in sorption up to 150 $\mathrm{mg} \mathrm{kg} \mathrm{kg}^{-1}$ (Essington, 2015). Some sorbent materials show a very pronounced increase in sorption by increasing sorbate concentration without any initial slope, which is a characteristic of the H-type isotherm (Dhananjay et al, 2016).

The cyhexatin sorption and desorption isotherms for sandy soil were well adjusted by the Langmuir model, obtaining a very characteristic profile. Sandy soil isotherms were similar to clayey soil.

Table 2 depicts the adjusted parameters from the isotherm mathematical modeling for azocyclotin and cyhexatin for both soils. The results indicate

Table 2 Adjusted parameters of sorption and desorption isotherms for azocyclotin and cyhexatin in clayey and sandy soil samples. $K_{j}, b_{j}, n_{j}$ are from the dual-mode F-L model; $K_{\text {sorb }}$ and $b_{\text {sorb }}$ are from the Langmuir model; desorption parameters are from both models

\begin{tabular}{ccccccccccc}
\hline Azocyclotin & $K_{1}$ & $K_{2}$ & $b_{1}$ & $b_{2}$ & $n_{1}$ & $n_{2}$ & $K_{\text {sorb }}$ & $b_{\text {sorb }}$ & $K_{\text {des }}$ & $b_{\text {des }}$ \\
\hline Clayey Soil & 0.242 & 5.20 & $4 \times 10^{-5}$ & 171 & 9.37 & 7.06 & - & - & 0.719 & 229 \\
Sandy Soil & 0.002 & 0.62 & $3 \times 10^{-4}$ & 120 & 3.30 & 0.96 & - & - & 0.336 & 137 \\
\hline Cyhexatin & $K_{1}$ & $K_{2}$ & $b_{1}$ & $b_{2}$ & $n_{1}$ & $n_{2}$ & $K_{\text {sorb }}$ & $b_{\text {sorb }}$ & $K_{\text {des }}$ & $b_{\text {des }}$ \\
\hline Clayey Soil & 0.583 & 20.7 & 11.5 & 148 & 2.23 & 2.98 & - & - & 2631 & 188 \\
Sandy Soil & - & - & - & - & - & - & 2.36 & 249 & 781 & 218 \\
\hline
\end{tabular}

a higher number of sorption sites $\left(b_{2}\right)$ with a higher azocyclotin-soil affinity $\left(K_{2}\right)$ for both soils and a low number of sorption sites $\left(b_{1}\right)$ with low affinity for azocyclotin $\left(K_{1}\right)$. For cyhexatin on clayey soil sorption, there was also a higher number of sites $\left(b_{2}\right)$ of more significant energy $\left(K_{2}\right)$, characterizing a higher sorption affinity and low mobility (Galunin et al, 2014). For sandy soil, it was not possible to distinguish between types of sorption sites. However, the affinity between cyhexatin and sandy soil, although low concerning the clayey soil, results in a low mobilization to the environment. In desorption, $K_{\text {des }}$ and $b_{\text {des }}$ were higher for clayey soil, indicating higher azocyclotin affinity post-desorption in addition to the higher number of occupied sites compared to sandy soil. Cyhexatin-soil affinity appeared to be much higher compared to azocyclotin-soil affinity. It is worth noting a higher cyhexatin-soil post-desorption affinity compared to post-sorption. Cyhexatin sorbed to the lower affinity sites comes out first, remaining only at the high-affinity sites. Azocyclotin presents a higher mobilization factor in the clayey soil, shown in Table 3. Although AZO has greater sorption capacity in clayey soil, its mobility 
$14 \quad$ Mobility of organotin pesticides: azocyclotin and cyhexatin in clayey and sandy soils
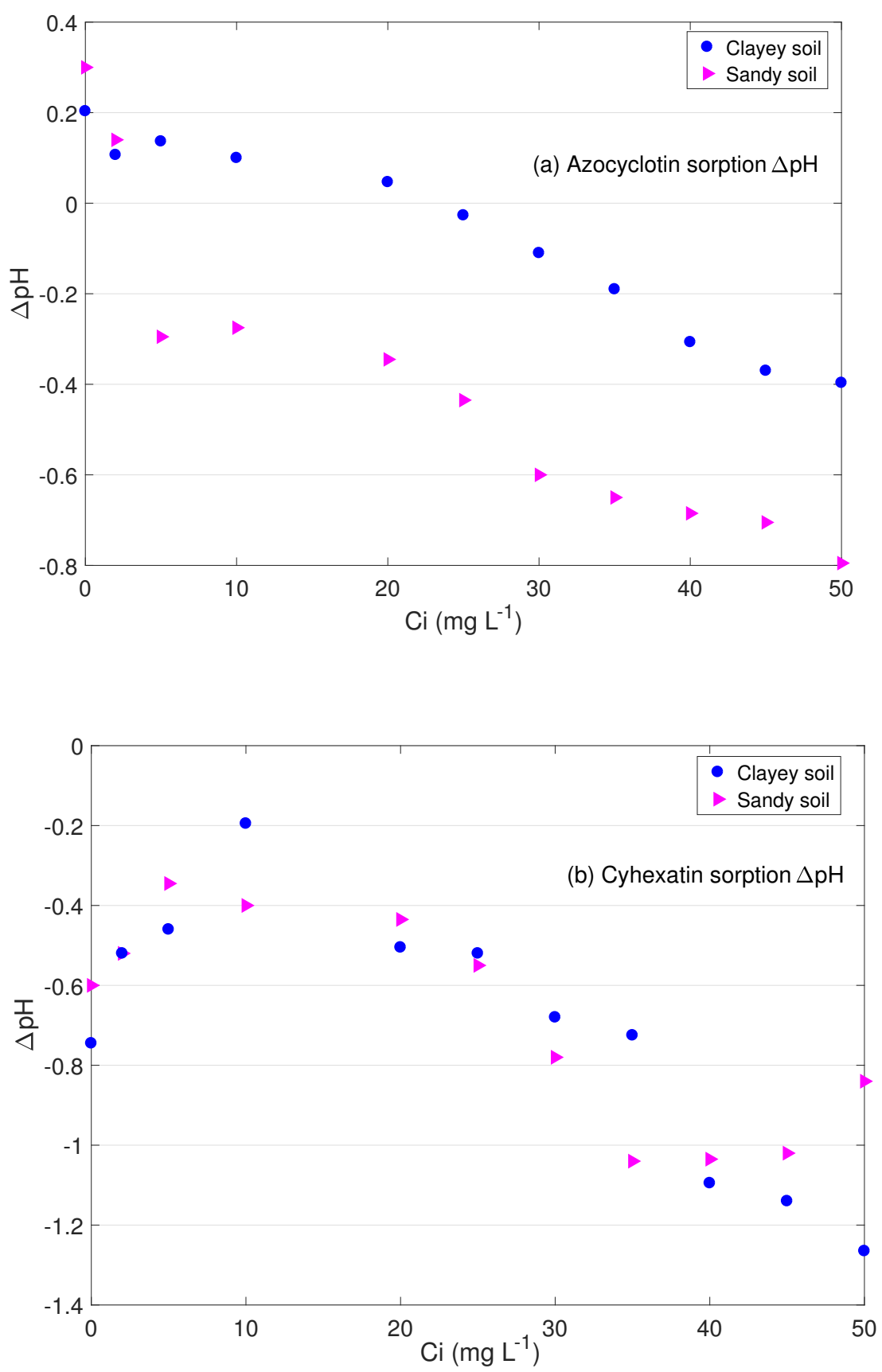

Fig. $6 \mathrm{pH}$ variation before and after sorption for azocyclotin (a) and cyhexatin (b), $\left(\mathrm{pH}_{i}\right.$ - $\mathrm{pH}_{f}$ ) on clayey and sandy soil samples 

cally non-hysteretic behavior in the sandy soil, with azocyclotin sorption and desorption occurring in the same proportion.

Table 3 Hysteresis Index and Mobilization Factor for azocyclotin and cyhexatin in both soil samples

\begin{tabular}{lccccc}
\hline Azocyclotin & $H I$ & $M F$ & Cyhexatin & $H I$ & $M F$ \\
\hline Clayey Soil & -0.146 & 0.235 & Clayey Soil & 0.003 & 0.001 \\
Sandy Soil & $7.8 \times 10^{-4}$ & 0.186 & Sandy Soil & 0.186 & 0.001 \\
\hline
\end{tabular}

The desorption steps determine the mobility of OTC in soils. The negative $H I$ in the clayey soil means mobilization. The $M F$ indicated low mobility of cyhexatin in clayey soil and higher mobility for azocyclotin in both soil types. The mobilization of azocyclotin determined in this study demonstrates the feasibility of traveling over long distances and establishes, to the best of our knowledge, both azocyclotin and cyhexatin as potentially toxic substances (PTS). Although of a different concept, the soil sorption constant $\left(\mathrm{K}_{o c}\right)$ can be used to interpret mobility. Swann et al (1983), using the reversedphase HPLC technique with refractive index detector and mobile phase 85:15 methanol:water, established $K_{o c}$ values from 2,000 to 5,000 as slight mobility. Thus, cyhexatin has been considered slightly mobile $\left(\mathrm{K}_{o c}: 4,365\right)$ based on some mobility studies (RS.Agricultural, 2017). Even though cyhexatin has shown slight mobilization in both types of soil, its mobility stands out as a secondary source of azocyclotin degradation.

\section{Conclusions}

The study of sorption and desorption processes of azocyclotin and cyhexatin was associated with the characterization and the structural soil composition and mobility of the OT compounds. The chromatographic method was validated and proved helpful for quantifying both OT species in soils by applying a simple sample preparation with ACN liquid-liquid extraction. Azocyclotin presented mobility in both clayey and sandy soils with $M F$ of $23.5 \%$ and $18.6 \%$ respectively, while cyhexatin was poorly mobile in both soils with $M F 0.1 \%$. As much as the results show, cyhexatin is still a metabolite of azocyclotin. One can, therefore, infer about the mobility of cyhexatin in the water table. Azocyclotin degrades to cyhexatin in the short term, implying an environmental risk associated with using azocyclotin and cyhexatin as pesticides.

Acknowledgments. The authors would like to thank Capes (Coordination for the Improvement of Higher Education Personnel) and State University of Londrina for their financial support and fellowships and the Spectroscopy Laboratory (LABESPEC), the Laboratory of X-ray Analysis (LARX) and the 
Analytical Instrumentation and Analytical Automation Development Laboratory (DIA) of UEL by FT-IR, XRD measurements and chromatography analysis

\section{Declarations}

Funding: The authors would like to thank Capes - Coordination for the Improvement of Higher Education Personnel for their financial support on fellowships.

Conflicts of interest/Competing interests - The authors have declared no conflict of interest.

Availability of data and material (data transparency)

Code availability: Not applicable

Authors' contributions - All authors whose names appear on the submission:

(i) made substantial contributions to the conception or design of the work; the acquisition, analysis, and interpretation of data, (ii) drafted the work or revised it critically for important intellectual content, (iii) approved the version to be published, and (iv) agree to be accountable for all aspects of the work in ensuring that questions related to the accuracy or integrity of any part of the work are appropriately investigated and resolved.

Ethics approval: Not applicable

Consent to participate: Not applicable.

Consent for publication: Not applicable.

\section{References}

Blahovec J, Yanniotis S (2009) Modified classification of sorption isotherms. J Food Eng 91(1):72 - 77. https://doi.org/10.1016/j.jfoodeng.2008.08.007

Blunden SJ, Evans CJ (1990) The handbook of environmental chemistry, vol 3. Springer Verlag, Berlim

Cheng P, Schachman H (1955) Studies on the validity of the einstein viscosity law and stokes law of sedimentation. J Polymer Science 16(1):19-30. https: //doi.org/10.1002/pol.1955.120168102

Constantino L, Quirino J, Abrao T, et al (2018) Sorption-desorption of antimony species onto calcined hydrotalcite: Surface structure and control of competitive anions. J Haz Mat 344:649 - 656. https://doi.org/10.1016/j. jhazmat.2017.11.016

Dhananjay K, Pandey L, Gaur J (2016) Metal sorption by algal biomass: From batch to continuous system. Algal Res 18:95-109. https://doi.org/10.1016/ j.algal.2016.05.026 
Mobility of organotin pesticides: azocyclotin and cyhexatin in clayey and sandy soils from th

Do D (1998) Adsorption analysis - equilibria and kinetics, vol 2. Imperial College Press, London

Ebdon L, Pitts L, Cornelis R, et al (2001) Trace Element Speciation for Environment, Food and Health. The Royal Society of Chemistry, London, https://doi.org/10.1039/9781847552204

Embrapa (2011) Manual of Soil Analysis. Brazilian Agricultural Research Company, Jardim Botanico, 1024 Rio de Janeiro, RJ, 2nd edn.

Essington M (2015) Soil and water chemistry, 2nd edn. CRC press, New York EU (2012) https://ec.europa.eu/, europen Union accessed January 2019

Fent K (1996) Ecotoxicology of organotin compounds. Crit Rev Toxicol 26:3117. https://doi.org/10.3109/10408449609089891

Fent K, Mueller M (1991) Occurrence of organotins in municipal wastewater and sewage sludge and behavior in a treatment plant. Environ Sci Technol 25:489-493. https://doi.org/10.1021/es00015a017

Furdek M, Mikac N, Bueno M, et al (2016) Organotin persistence in contaminated marine sediments and porewaters: In situ degradation study using species-specific stable isotopic tracers. J Hazard Mater 307:263-273. https://doi.org/10.1016/j.jhazmat.2015.12.037

Galunin E, Alba MD, Santos MJ, et al (2010) Lanthanide sorption on smectitic clays in presence of cement leachates. Geochim Cosmochim Acta 74(3):862875. https://doi.org/10.1016/j.gca.2009.11.003

Galunin E, Ferreti J, Zapelline I, et al (2014) Cadmium mobility in sediments and soils from a coal mining area on Tibagi River watershed: Environmental risk assessment. J Haz Mat 265:280 - 287. https://doi.org/10.1016/j. jhazmat.2013.11.010

Giacalone A, Gianguzza A, Petignano A, et al (2006) Sequestration of organometallic compounds by natural organic matter. binding of trimethyltin(IV) by fulvic and alginic acids. Applied Organometallic Chem 20(10):706-717. https://doi.org/10.1002/aoc.1128

Gobbo F, Sarita P, Karina P (2015) High precision and selectivity for quantitation of enrofloxacin and ciprofloxacin in five chicken tissues using solid phase extraction and esi lcms for application in monitoring residues. Anal Methods 7:3291-3297. https://doi.org/10.1039/c4ay02962c

Godoi A, Favoreto R, Santiago S (2003) Environmental contamination for organotin compounds. Quim Nova 26:708-716. https://doi.org/10.1590/ 


\section{S0100-40422003000500015}

Gui W, Tian C, Sun Q, et al (2016) Simultaneous determination of organotin pesticides by hplc-icp-ms and their sorption, desorption, and transformation in freshwater sediments. Water Res 95:185-194. https://doi.org/10.1016/j. watres.2016.02.056

Guidelines HT (2005) ICH Validation of Analytical Procedures: Text and Methodology. ICH Harmonized Tripartite Guidelines

Huang J, Matzner E (2004) Adsorption and desorption of organotin compounds in organic and mineral soils. Eur J Soil Sci 55(4):693-698. https: //doi.org/10.1111/j.1365-2389.2004.00634.x

Joan A, Rozing J, Hattum V, et al (1992) Normal-phase high-performance liquid chromatography with uv irradiation, morin complexation and fluorescence detection for the determination of organotin pesticides. J Chromatogr A 609:195 - 203. https://doi.org/10.1016/0021-9673(92)80163-O

Jones AD, Bruland GL, Agrawal SG, et al (2005) Factors influencing the sorption of oxytetracycline to soils. Environ Toxicol Chem 24(4):761-770. https://doi.org/10.1897/04-037R.1

Kanimozhi V, Palanivel K, Akbarsha M (2016) Tributyltin-mediated hepatic, renal and testicular tissue damage in male syrian hamster (mesocricetus auratus): a study on impact of oxidative stress. SpringerPlus 5:1523. https: //doi.org/10.1186/s40064-016-3186-1

Langmuir L (1916) The constitution and fundamental properties of solids and liquids. J Am Chem Soc 11:221-2295. https://doi.org/10.1021/ja02268a002

Ming H, Margaret A, Rav N, et al (2012) Persistent toxic substances: sources, fates and effects. Rev Environ Health 27:207-213. https://doi.org/10.1515/ reveh-2012-0040

Muller M, Markus D (1987) Degradation and residues of cyclohexyltin compounds in orchard soil following field application of cyhexatin. Bul Environ Contam Toxicol 38:627-633. https://doi.org/10.1007/bf01608595

Ning M, Gui W, Zhu G (2015) The analysis of azocyclotin and cyhexatin residues in fruits using ultrahigh-performance liquid chromatographytandem mass spectrometry. Anal Methods 7:2108-2113. https://doi.org/10. 1039/C4AY02624A

Oliveira R, Santelli R (2010) Occurrence and chemical speciation analysis of organotin compounds in the environment: A review. Talanta 82:9-24. https: //doi.org/10.1016/j.talanta.2010.04.046 
Mobility of organotin pesticides: azocyclotin and cyhexatin in clayey and sandy soils from th

Perez R, Barasoain F (1983) High-performance liquid chromatographic determination of cyhexatin in technical and wettable pesticide powders. J Chromatogr A 260:200 - 205. https://doi.org/10.1016/0021-9673(83)80027-2

PubChem (2017a) https://pubchem.ncbi.nlm.nih.gov/compound/Cyhexatin, accessed November 2021

PubChem (2017b) https://pubchem.ncbi.nlm.nih.gov/compound/Azocyclotin, accessed November 2021

RS.Agricultural (2017) https://www.ars.usda.gov, accessed January 2019

Silva R, Guerra D (2013) Use of natural and modified kaolinite/ilite as adsorbent for removal methylene blue dye from aqueous solution. J Chil Chem Soc 58(1):1517-1519. https://doi.org/10.4067/S0717-97072013000100003

Sithole BB, Guy RD (1987) Models for tetracycline in aquatic environments ii interaction with humic substances. Water Air Soil Pollut 32:315-321. https: //doi.org/10.1007/bf00225117

Sparks D (1995) Environmental soil chemistry. Academic Press, Book Marketing Department, San Diego

Swann RL, Laskowski DA, McCall PJ, et al (1983) A rapid method for the estimation of the environmental parameters octanol/water partition coefficient, soil sorption constant, water to air ratio, and water solubility. Residue Rev pp 7-28. https://doi.org/10.1007/978-1-4612-5462-1_3

Tomasz T, Jan S (2009) Application of hplc-dad and tlc-dad after spe to the quantitative analysis of pesticides in water samples. J Liq Chromatogr Relat Technol 32:1241-1258. https://doi.org/10.1080/10826070902854391

Walkley A, Black I (1934) An examination of the degtjareff method for determining soil organic matter and a proposed modification of the chromic acid titration method. Soil Sci 37:29 - 38. https://doi.org/10.1097/ 00010694-193401000-00003

Xiupin W, Lan D, Huarong Z, et al (2006) Development of an analytical method for organotin compounds in fortified flour samples using microwaveassisted extraction and normal-phase hplc with uv detection. J Chromatogr B 843:268-274. https://doi.org/10.1016/j.jchromb.2006.06.013 


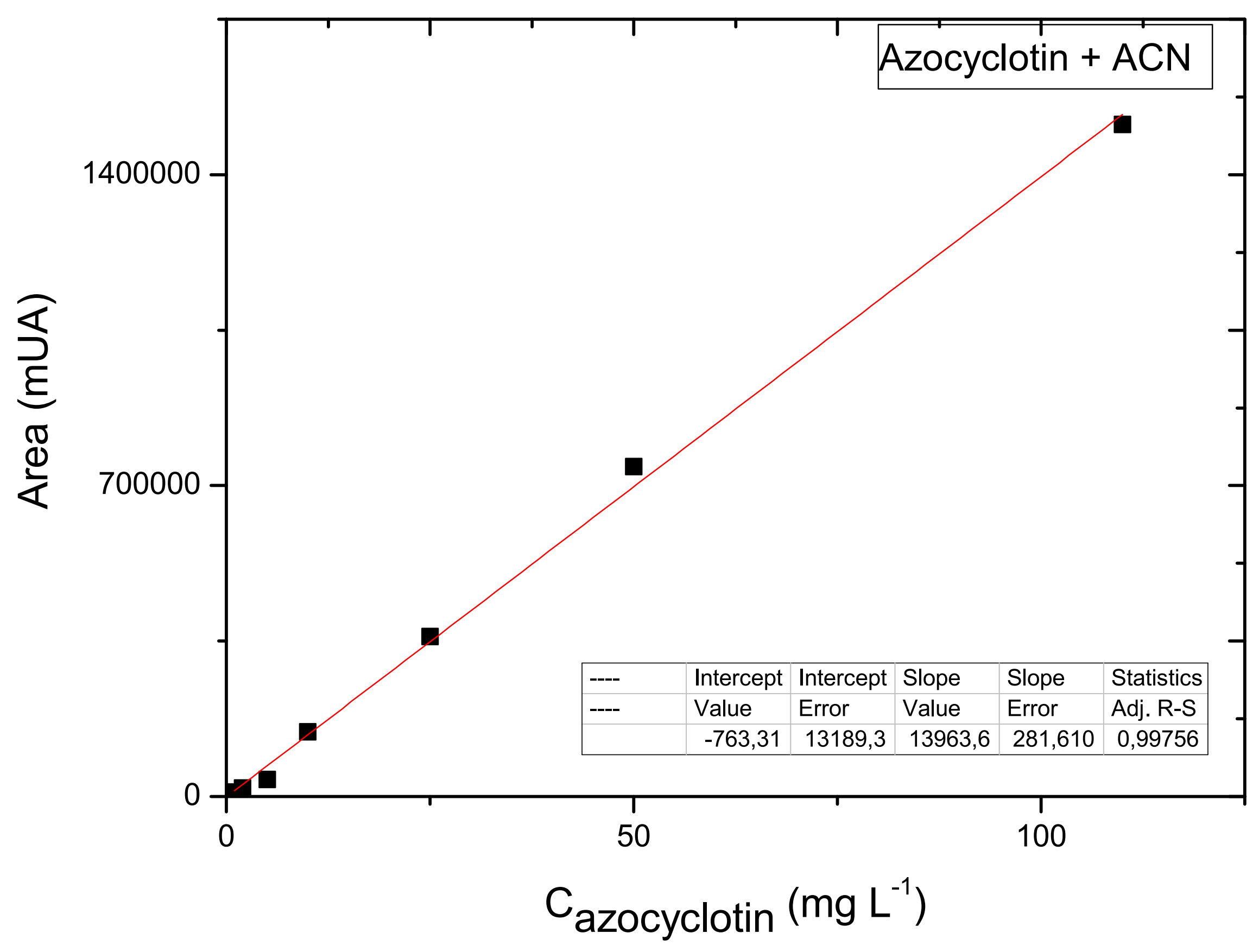




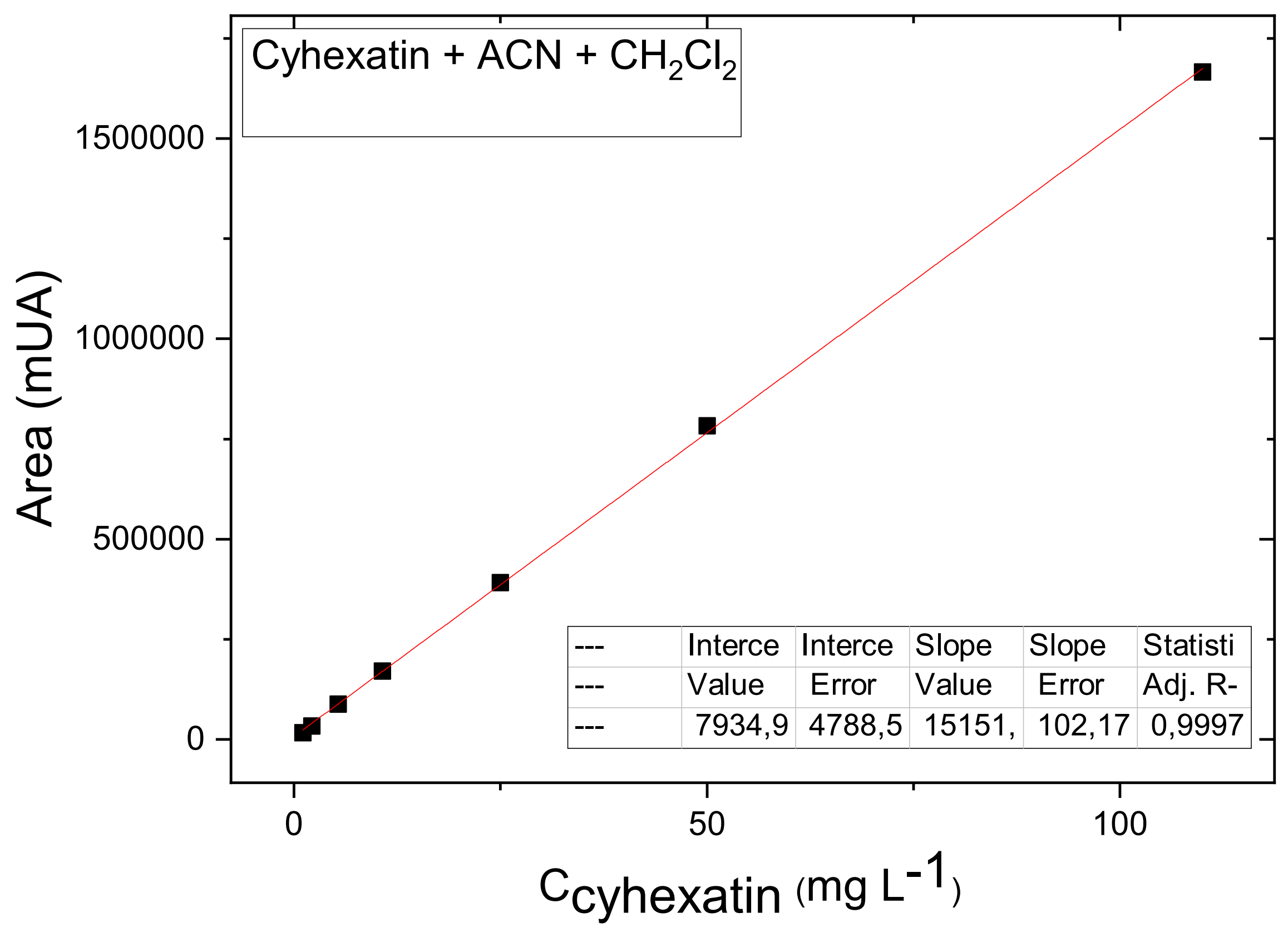




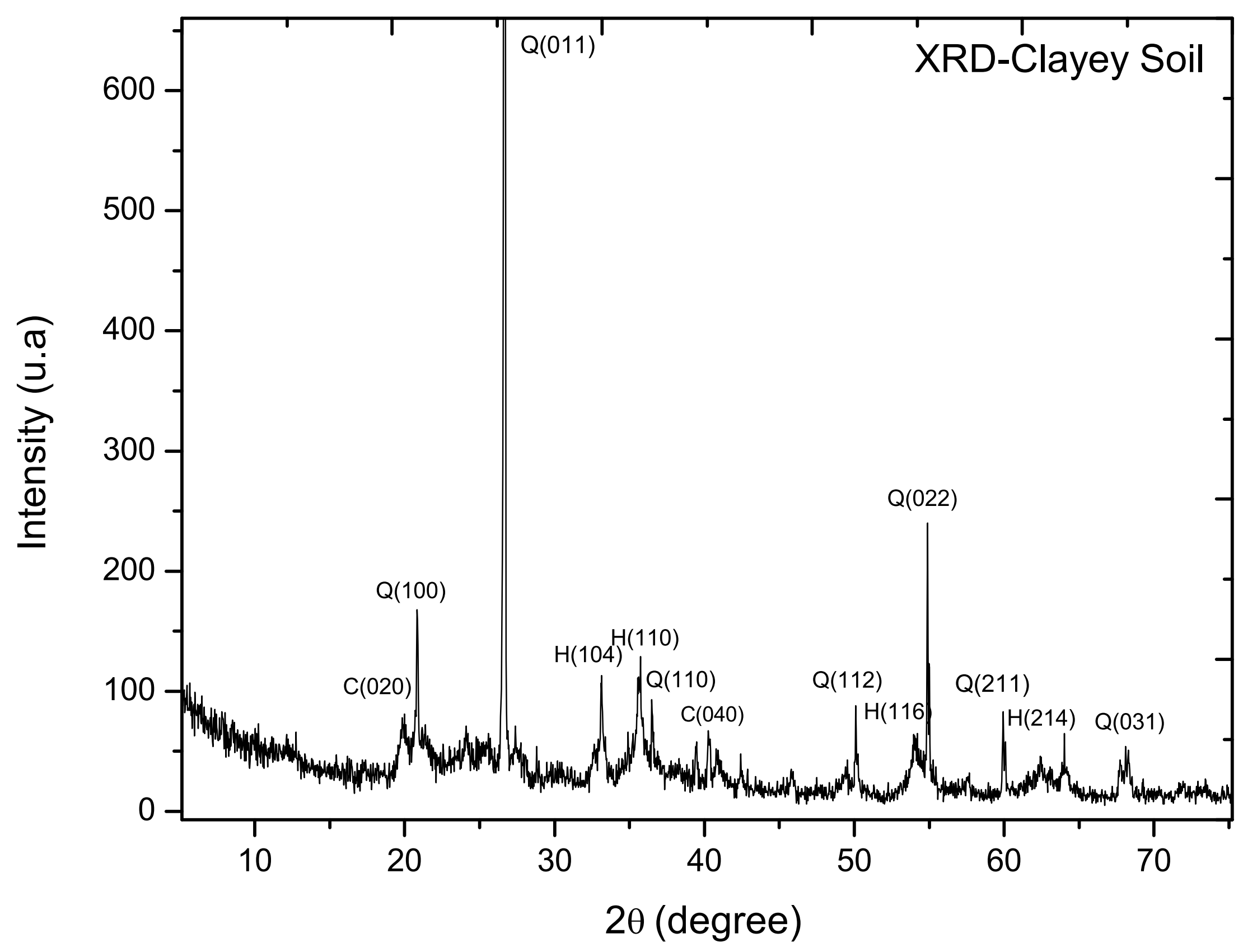




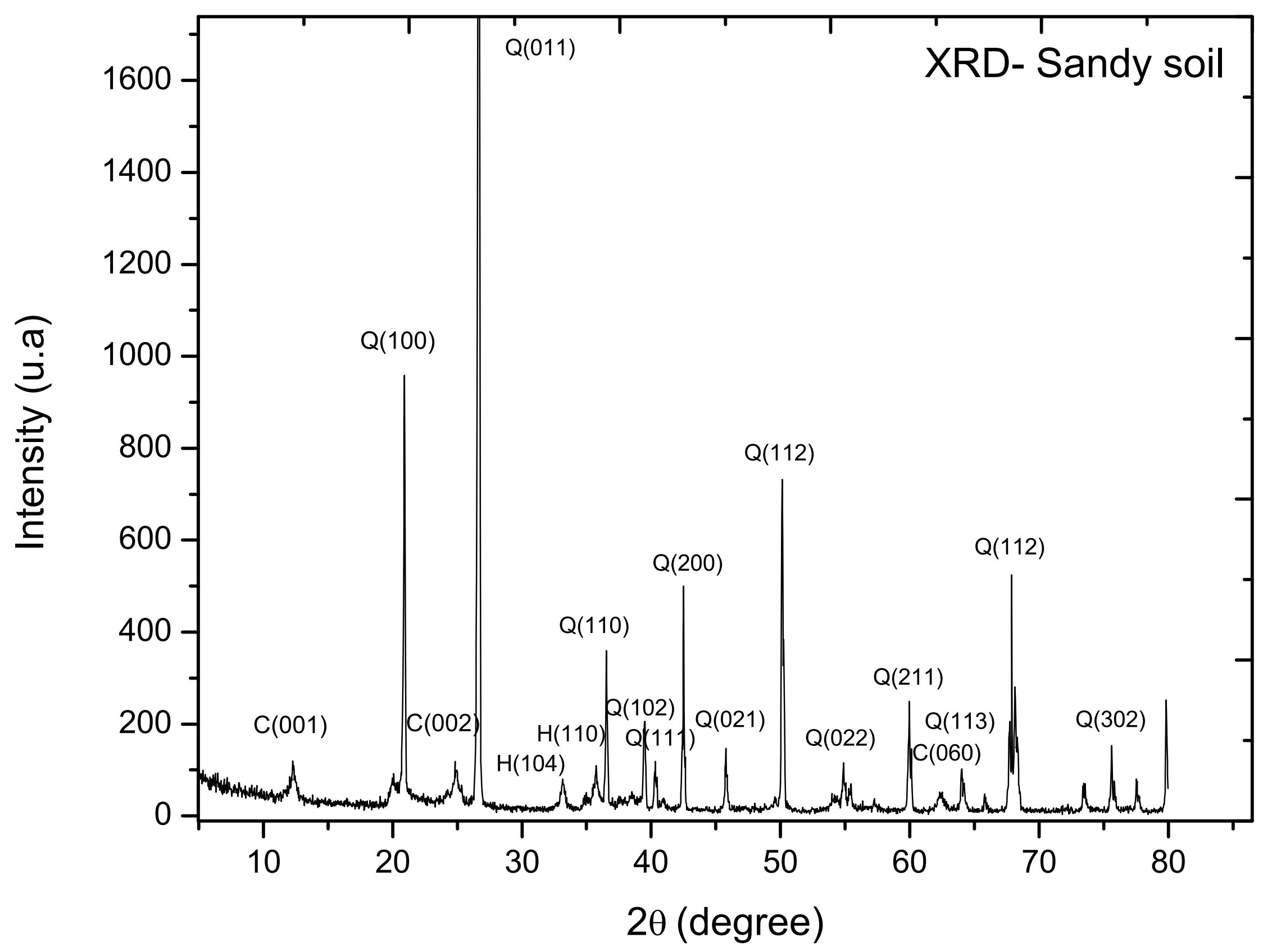




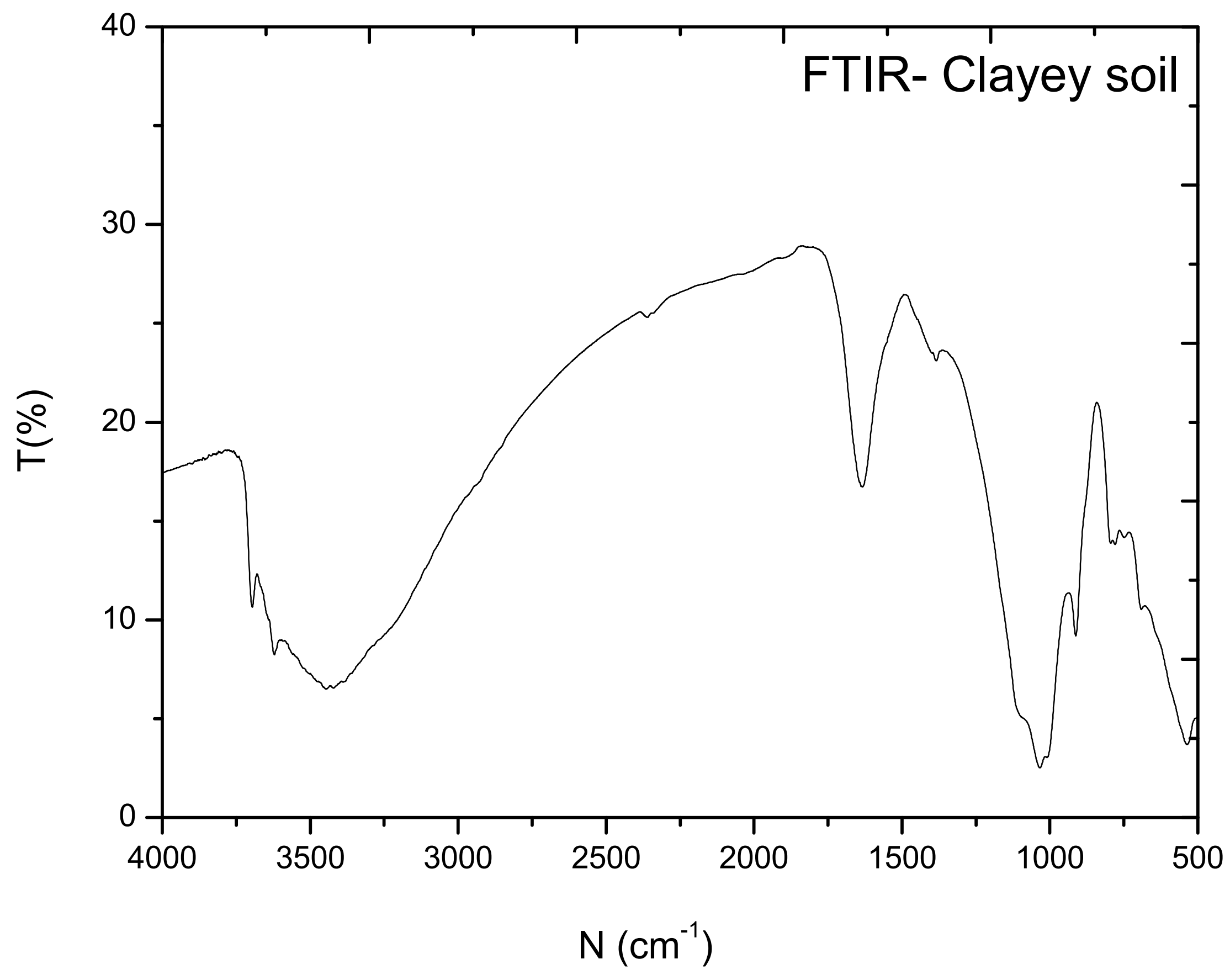




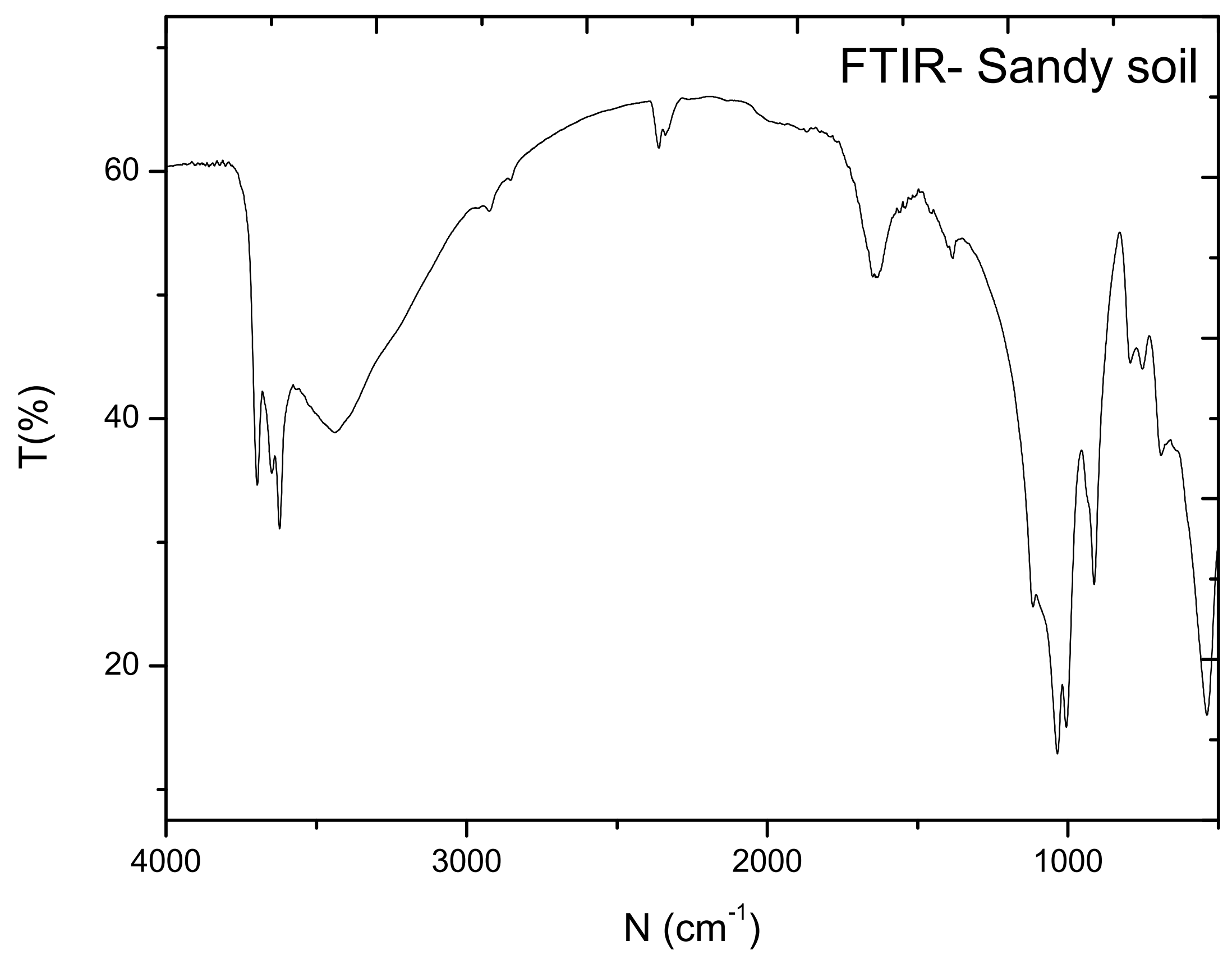




\section{Supplementary Files}

This is a list of supplementary files associated with this preprint. Click to download.

- SMAZOCHT.pdf

- graphicalabstract.pdf 